\title{
DESIGN AND TEST OF A LARGE PLASMA TORCH FOR ENVIRONMENTAL RECYCLING
}

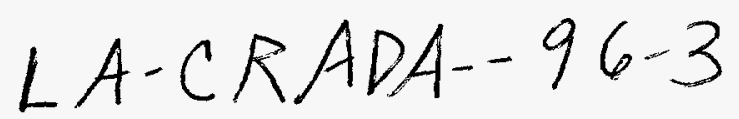

\section{Small Business Initiative CRADA \# LA95C10206}

PI: Michel Tuszewski (P-24)

Industrial Partner: Plasma Technology Inc.

\section{Final abstract}

A 2.5-inch inductive plasma torch has been tested with up to $600 \mathrm{~kW}$ if power and with argon, nitrogen, and oxygen gases. A complete power balance is obtained from electrical, thermal, and radiation measurements. These data indicate that torch efficiencies of up to $30 \%$ are obtained with molecular gases, while efficiencies around $15 \%$ are obtained with argon. The efficiencies obtained with molecular gases almost triple earlier torch efficiencies and confirm substantially the predictions of a torch model developed during a previous CRADA. Torch efficiencies of up to $50 \%$ could be obtained in future tests with an improved if power supply, with steam gas, and with larger torch dimensions.

\section{DISCLAIMER}

This report was prepared as an account of work sponsored by an agency of the United States Government. Neither the United States Government nor any agency thereof, nor any of their employees, makes any warranty, express or implied, or assumes any legal liability or responsibility for the accuracy, completeness, or usefulness of any information, apparatus, product, or process disclosed, or represents that its use would not infringe privately owned rights. Reference herein to any specific commercial product, process, or service by trade name, trademark, manufacturer, or otherwise does not necessarily constitute or imply its endorsement, recommendation, or favoring by the United States Government or any agency thereof. The views and opinions of authors expressed herein do not necessarily state or reflect those of the United States Government or any agency thereof. 


\section{DISCLAIMER}

Portions of this document may be illegible electronic image products. Images are produced from the best available original document. 


\section{DESIGN AND TEST OF A LARGE PLASMA TORCH FOR ENVIRONMENTAL RECYCLING}

\section{Project Accomplishment Summary}

Small Business Initiative CRADA \#: LA95C10206

DOE TTI \#: 93-LANL-2-XX

Industrial Partner: Plasma Technology Inc.

\section{Background:}

Results from a previous CRADA "Assessment of Heat Losses in an Induction Coupled RF Plasma Heat Generator for Environmental Recycling" have shown that commercially attractive plasma torch efficiencies require the use of somewhat larger-diameter torches and of molecular gases. Hence, the present research aimed at (1) testing the present 2.5-inch-diameter torch with molecular gases such as nitrogen and oxygen, and (2) design and test a larger plasma torch. PTI seeked help from LANL for both tasks.

\section{Description:}

A 2.5-inch metal walled inductive plasma torch was tested from 12/94 to 2/95 with an industrial type $600 \mathrm{~kW}, 400 \mathrm{kHz}$ radio frequency power supply. Torch efficiencies (exit gas power divided by input electrical power) of up to $30 \%$ were obtained with nitrogen and oxygen gases, about twice those achieved with argon. LANL contributed two measurements to the above power balance.

First, the input power to the torch coil was determined by measuring the coil voltage, coil current, and phase angle. These data indicate that about $60 \%$ of the electrical input power was consistently transferred to the coil. Hence, power losses in the rectifier, in the if power tubes, and in the transmission line to the coil were about $40 \%$. These results are roughly consistent with the if power supply rating of $30 \%$ power loss.

Second, an estimate of the radiative power losses from argon plasmas was made with a bolometer. This instrument monitors the steady-state temperature increase of a 50-micrometer-thick stainless steel foil exposed to the radiation leaving the torch. The radiation from a small solid angle is 
collected through a sapphire window. The temperature rise results from a balance between radiative heating of the foil and radial thermal conduction losses to the foil outer boundary. Data obtained for various conditions indicate that the argon plasma radiative losses are substantial, typically $15-20 \%$ of the input electrical power. This suggests high argon plasma temperatures, excessive radiative losses, and associated poor torch efficiencies with argon gas.

The higher torch efficiencies obtained with nitrogen and oxygen gases confirm substantially the predictions of a torch model developed during the previous CRADA "Assessment of Heat Losses in an Induction Coupled RF Plasma Heat Generator for Environmental Recycling". Torch efficiencies of up to $50 \%$ could be obtained in future tests with an improved if power supply (solid state rather than vacuum tube), with steam gas (which provides very high exit gas enthalpies), and with larger torch dimensions (to avoid excessive plasma temperatures and to minimize radiative losses). Unfortunately, the design, construction, and test of a larger plasma torch could not be made up to now due to unsufficient research and development funds. Hence, the second task of the present CRADA could not be completed as of today.

\section{Economic impact:}

The development of a $0.6-1 \mathrm{MW}$ inductive plasma torch with $40-50 \%$ efficiency would be a very significant step for environmental recycling. Present torch efficiencies are $10-20 \%$. If successful, this torch development would soon be incorporated by PTI in its PERC commercial units for waste destruction. This would allow PTI to establish several new jobs in Northem New Mexico. Based on long term business success, PTI would invest in facilities, either at LANL or around Santa $\mathrm{Fe}$, creating employment and subcontracts to New Mexico.

\section{Benefits to DOE:}

This project supports the research and development of a critical technology in a worldwide market that both meets defense needs and has commercial potential. Stockpiles of conventional weapons pose a national security threat that are cost effective, environmentally friendly, and result in usable by-products. Future applications of the PERC process could include the high explosives of DOE's nuclear weapons, chemical and biological remediation, and the treatment and volume reduction of radioactive mixed waste. 


\section{Project status:}

The first task of the project was successfully completed. Torch efficiencies of up to $30 \%$ have been obtained, a very significant step towards commercialization. These results show promise for even larger efficiencies with a somewhat larger torch and with steam gas. However, at the present time, a new larger torch could not be designed, built, and tested by PTI due to unsufficient research and development funds. Hence, the second task of the project remains incomplete.

\section{DOE Facility Point of Contact for Project information:}

Michel Tuszewski,

phone: 667-3566,

fax: 665-3552, email: mgtu@lanl.gov,

Los Alamos National Laboratory, P-24, MS E526.

\section{Company Size and Point of Contact:}

Plasma Technology Inc. (PTI) is a small business headquartered in Santa Fe, New Mexico. Street Address: 1800 Old Pecos Trail, Suite O, Santa Fe, NM 87505. Contact: John Serino, CEO. Phone: 505-988-4943. Fax: 505-988-8015. PTI provides its Plasma Energy Recycle and Conversion (PERC) process, technology, equipment, and engineering services to equipment users involved in destruction of waste into usable by-products. PTI has currently 3 full-time employees and a 1995 revenue of $1.5 \mathrm{M} \$$.

\section{Project examples:}

Recently, PTI has successfully demonstrated operation of a $0.7 \mathrm{MW}$ argon plasma torch and associated PERC equipment designed for recycling of conventional munitions. A video of the plasma tests performed during the present CRADA is available from the company. 